\title{
New Thieme Research Awards: Call for Pacesetting Contributions to Drug Research
}

Authors

Affiliations

\author{
M. Wehling ${ }^{1}$, R. Wenzel \\ ${ }^{1}$ Institute for Experimental and Clinical Pharmacology and Toxicology, Ruprecht-Karls-Universität Heidelberg, Mannheim, \\ Germany \\ Georg Thieme Verlag KG, Stuttgart, Germany
}

\section{Bibliography}

DOI http://dx.doi.org/

10.1055/s-0042-109873

Drug Res 2016;

66: 337

(c) Georg Thieme Verlag KG

Stuttgart · New York

ISSN 2194-9379
Drug Research celebrates its $65^{\text {th }}$ birthday this year demonstrating both the visionary power of the founder, [name], and the scientific success of myriads of authors, several editors and 2 publishers. No doubt, innovative pace in drug development and, thus, pharmacotherapy has steadily increased, and major breakthroughs - though not evenly distributed across all therapeutic areas can be witnessed at a growing rate.

Only recently at the occasion of transition from Edition Cantor to Thieme as publisher, the development of the Journal was promoted by the complete transition to English as only language of the publication as well as by the accentuation of its translational orientation.

These changes were accompanied by the introduction of an electronic submission system resulting in facilitation of the world-wide access of authors to the Journal, and the acceleration of the peer-review system. In 2015, the mean time between submission and final editorial decision was only 37 days.

Though those changes were essential to secure the future of the Journal in an ever increasingly competitive environment of scientific journals, further means need to be instituted to strengthen its resilience. As a timely measure to promote the successful Journal, we proudly announce the endowment of the Thieme Awards for the Most Innovative Original Paper and for the Best Critical Review.

These prizes will be issued to stimulate and support scientific efforts by awarding EUR 3000 each for the most innovative original research paper as well as for the best critical review on any of the core subjects of Drug Research to be published in the journal within the next 18 months. To second the major scientific orientation of the Journal, contributions with distinct translational relevance will be prioritized.

\section{Description of Awards $\nabla$}

Drug Research invites you to submit your best research papers or critical and comprehensive reviews in order to secure your chance to win one of these prestigious awards. The two winning authors/authors' teams will receive EUR 3000 in both categories, and the prizes will be awarded during the annual conference of the German Society for Pharmacology and Toxicology (DGPT) in 2018. The winning contribution will be chosen by a jury comprising the Editorin-Chief, an Advisory Board of outstanding scientists and a representative of the DGPT.

i) Criteria of eligibility for the Most Innovative Original Paper are: relevant research purpose aiming at major unmet medical needs, scientific rigor, adequate design, execution and interpretation of investigations, novelty/innovation and translational orientation.

ii) Criteria of eligibility for the Best Critical Review are: relevant research topics aiming at major unmet medical needs, compliance with current standards of scientific reviews, in particular systematic reviews, added value against the background of related reviews elsewhere, comprehensiveness balanced against readability and volume.

All work must be original and must not have been published previously. Deadline: Please submit your contribution by June the $30^{\text {th }}$, 2017, to be eligible for these awards. Please state clearly that you wish your work to be considered for these awards when submitting. Also, clearly indicate who would be the primary recipient in case of multiple authors.

Only papers submitted through the online submission site will be considered:

https://mc.manuscriptcentral.com/drugres

We hope that the scientific competition induced by the awards will not only increase the visibility of the Journal, but - as the main objective -help to inspire and support scientists to produce highly relevant and clinically oriented research in the realm of pharmacotherapy.

Prof. Martin Wehling,

Editor-in-Chief

\section{Dr. Regina Wenzel,} Thieme Publishers 